\title{
Determinants of acceptance of cervical cancer screening in Dar es Salaam, Tanzania
}

\author{
Crispin Kahesa ${ }^{1,2}$, Susanne Kjaer ${ }^{3}$, Julius Mwaiselage², Twalib Ngoma², Britt Tersbol', Myassa Dartell ${ }^{1,3}$ \\ and Vibeke Rasch ${ }^{1,4^{*}}$
}

\begin{abstract}
Objective: To describe how demographic characteristics and knowledge of cervical cancer influence screening acceptance among women living in Dar es Salaam, Tanzania.

Methods: Multistage cluster sampling was carried out in 45 randomly selected streets in Dar es Salaam. Women between the ages of 25-59 who lived in the sampled streets were invited to a cervical cancer screening; 804 women accepted and 313 rejected the invitation. Information on demographic characteristics and knowledge of cervical cancer were obtained through structured questionnaire interviews.

Results: Women aged 35-44 and women aged 45-59 had increased ORs of 3.52 and 7.09, respectively, for accepting screening. Increased accepting rates were also found among single women (OR 2.43) and among women who had attended primary or secondary school (ORs of 1.81 and 1.94). Women who had 0-2 children were also more prone to accept screening in comparison with women who had five or more children (OR 3.21). Finally, knowledge of cervical cancer and awareness of the existing screening program were also associated with increased acceptance rates (ORs of 5.90 and 4.20).
\end{abstract}

Conclusion: There are identifiable subgroups where cervical cancer screening can be increased in Dar es Salaam. Special attention should be paid to women of low education and women of high parity. In addition, knowledge and awareness raising campaigns that goes hand in hand with culturally acceptable screening services will likely lead to an increased uptake of cervical cancer screening.

Keywords: Cervical cancer, Screening acceptance, Demographic characteristics, Knowledge, Tanzania

\section{Background}

With an estimated 500,000 new cases and the cause of 273,000 deaths each year, cervical cancer is one of the most prevalent and deadly female cancers worldwide. The vast majority of cervical cancer cases $(99,7 \%)$ are linked to genital infection with human papillomavirus (HPV) [1], a common virus that is sexually transmitted [2]. Sub-Saharan Africa is by far the most affected region, accounting for $80 \%$ of the new cases and $85 \%$ of the deaths from cervical cancer worldwide [3]. In developed countries with well-established screening programs, the incidences of cervical cancer have been

\footnotetext{
* Correspondence: vrasch@health.sdu.dk

'Department of International Health, Immunology and Microbiology,

University of Copenhagen, Copenhagen K, Denmark

${ }^{4}$ Department of Gynaecology and Obstetrics, Odense University Hospital, Denmark

Full list of author information is available at the end of the article
}

reduced by $70-90 \%[4,5]$. In contrast, in developing countries where access to screening services for cervical cancer is often limited or nonexistent the incidence of women affected by the disease continues to exist at high levels [6-8].

In the developed world, the introduction of pap smear as a screening test modality has led to a reduction of the burden of cervical cancer. However, there are several factors that, in addition to the availability of a screening test, contribute to reducing the burden of cervical cancer. These include prevalence rates of HPV, effective screening strategies, availability of facilities for diagnostic follow up and prompt treatment of detected lesions. The participation rate in cervical cancer screening is of utmost importance for the effectiveness of a cervical cancer screening program $[9,10]$. The adoption of pap smear as a screening approach in the developing world 
has been found to be impractical due to the lack of trained cytotechnologists, cytology laboratories and inefficient health systems [5,11]. In an effort to curb the burden of cervical cancer in developing countries, the World Health Organization (WHO) and the International Agency for Research on Cancer (IARC) have established cervical cancer screening programs by adopting an alternative screening method based on visual inspection with acetic acid (VIA) [12,13]. The VIA test has proven to have similar sensitivity to that of cytology but lower specificity and positive predictive value when evaluated in clinical research settings [14]. Experiences from Tanzania indicate that when VIA test is introduced for wide-spread routine use it may be at the cost of poorer test performance [15].

When focusing on Tanzania, cervical cancer is, with an estimated incidence rate of $68.6 / 100,000$, the leading cause of cancer and cancer-related deaths [16]. This incidence rate is also high when compared to other subSaharan African countries. At Tanzania's only cancer center, the Ocean Road Cancer Institute in Dar es Salaam, $80 \%$ of cervical cancer patients have already progressed to a late, incurable stage by the time women present themselves for medical care. Acknowledging the increasing burden of the disease, a cervical cancer screening program based on VIA test was established in Dar es Salaam with support from WHO, IARC and the International Network for Cancer Treatment and Research in 2002. An evaluation of the program documented that the VIA test was effective as a screening test for cervical cancer prevention and it was decided to offer VIA testing for routine use [17]. The routine program is targeting approximately 500,000 women living in Dar es Salaam. Five years after project implementation, screening attendance was evaluated and it was found that only $4 \%$ of the target population had been screened. To address the poor screening coverage, the cervical cancer screening program in Tanzania has undergone several iterations in recent years. Despite these efforts, the available screening resources are still not utilized by the vast majority of women living in Dar es Salaam [18].

To inform the strategy for future scale-up of cervical cancer screening and better reach women with cervical cancer screening services, this paper focuses on a group of women who were invited to attend the cervical cancer screening program in Dar es Salaam and describes how demographic characteristics and knowledge of cervical cancer are associated with screening acceptance.

\section{Methods}

\section{Study setting}

The study was carried out among women aged between 25-59 years living in Dar es Salaam, Tanzania. Based on the 2002 Population and Housing Census, Dar es Salaam had 2,487,288 inhabitants, of whom 700,000 were women in a reproductive age group. Ninety-five percent of the residents are engaged in the non-formal sector and the rest are formally employed. Women are mainly involved in the domestic sphere and the literacy level is more than $50 \%$. The city is divided into three municipal councils: Kinondoni, Ilala and Temeke. The population is served by one national hospital, three municipal hospitals and a number of private hospitals and dispensaries. Additionally, Dar es Salaam has the only centre for specialized cancer care in Tanzania, Ocean Road Cancer Institute. The study population comprised of a group of women from the general population who were aged $25-59$ years and who had never attended cervical cancer screening (Figure 1).

\section{Study population}

To identify a representative group of women, multistage cluster sampling was performed where three wards from each of the three municipals in Dar es Salaam were randomly selected. In all 6063 women in the age group 25-59 years were living in the nine sampled wards. Five streets were subsequently selected randomly from each of the wards. Two strategies were employed to recruit the study participants. The first approach was home visits performed by the principal investigator and research assistants with help from the community leaders from the respective streets in Kinondoni municipal. In all 431 women were considered eligible for the study, 35 of these women were not included in the study since they were either not at home when attempted visited or stated they had previously attended screening. The remaining 396 women were interviewed and afterwards provided with health education on cervical cancer and invited to attend screening at Ocean Road Cancer Institute. Only 83 women accepted the invitation. The second approach relied on combination of outreach services and awareness raising campaigns. This approach was used in the two remaining municipals, Temeke and Ilala. Through campaigns that were conducted by means of megaphones in the sampled streets, women were provided with health information and invited to attend outreach screening for cervical cancer at the municipal hospitals. In all, 807 women showed up for screening, 86 of these women were excluded from the study sample because they were either living outside the selected streets $(n=41)$ or had previously attended screening $(n=45)$.

\section{Data collection and analyses}

Structured questionnaire interviews focusing on demographic characteristics and knowledge and awareness of cervical cancer were performed among the 1117 women who were either visited at home and invited to attend screening or had attended screening after awareness raising campaigns. To assess how demographic characteristics 


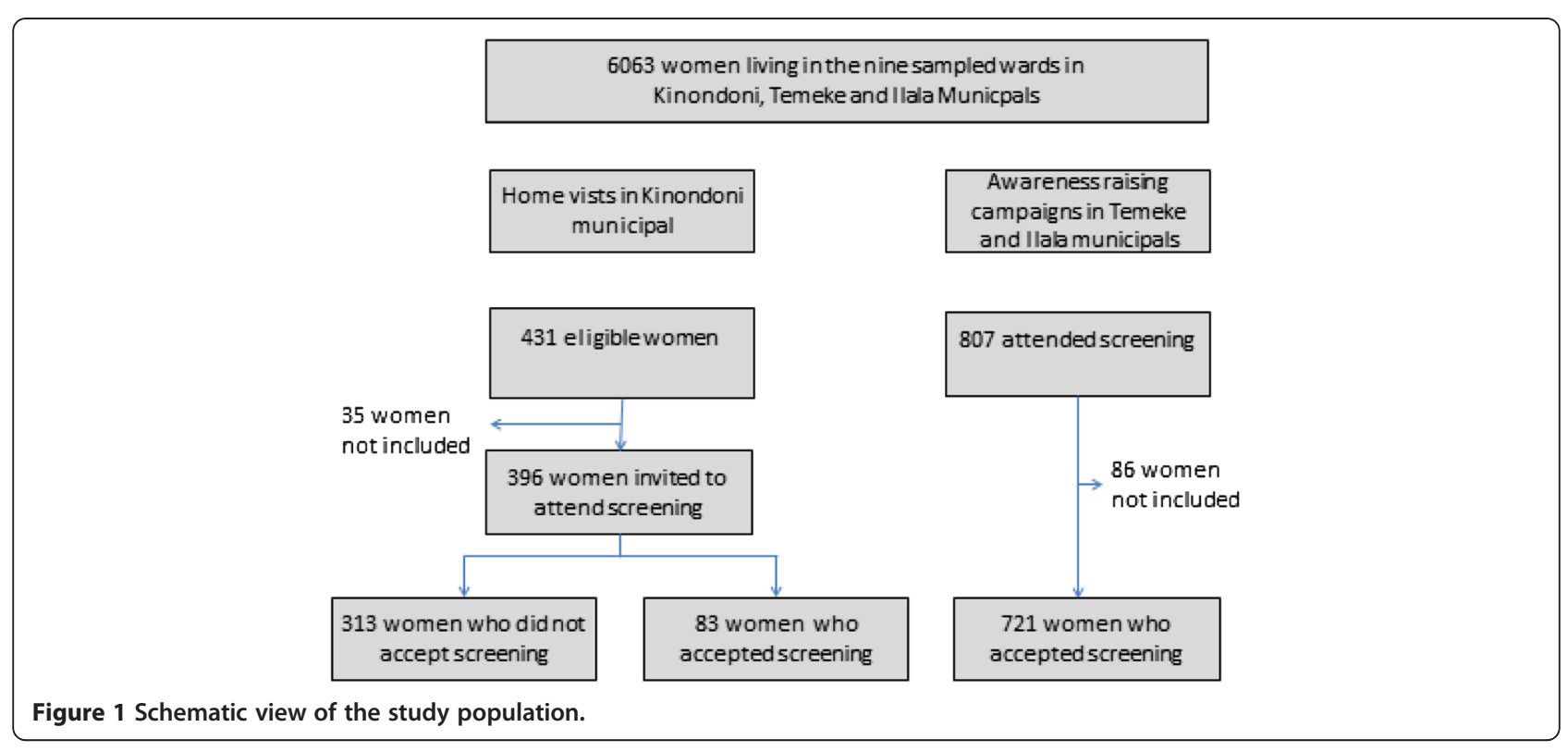

were associated with screening acceptance, we compared age, marital status, educational level and number of children between the 804 women who accepted screening after either home visit or awareness raising campaigns and the 313 women who did not accept the screening invitation. The association between screening acceptance and knowledge and awareness of cervical cancer was determined through a comparison of the 83 women from the home visit group who accepted screening and the 313 women from the home visit group who did not accept the screening invitation.

Data were entered in EPIINFO version 6.04 and then exported to SPSS version 13 for analysis. Crude odds ratios (ORs) with 95\% confidence interval (CI) were calculated where the women's screening acceptance comprised the dependent variable and demographic characteristic and factors related to the women's knowledge of cervical cancer the independent variables. Adjusted analysis was performed by means of multiple logistic regression, where the influence of age, marital situation, parity and educational level were controlled for.

Permission to carry out the study was obtained from the Tanzania National Institute of Medical Research and the Danish National Committee on Biomedical Research Ethics. Verbal informed consent to participate in the study was obtained from participants. Participants who were found to have medical problems were assisted to visit the referral hospital for further management and treatment.

\section{Results}

The demographic characteristics of the general population together with the demographic characteristics of the 83 women who accepted screening after home visits and the 721 women who accepted screening after awareness raising campaigns are summarized in Table 1. Women who attended screening after home visits or awareness raising campaigns were more often aged 45-59 (21\% and $23 \%$, respectively), were more often married $(80 \%$ and $78 \%$, respectively) and had more often attended secondary school (58\% and 33\%, respectively) in comparison with the general population where the corresponding figures were $12 \%, 63 \%$ and $16 \%$. In addition, the women who accepted screening after home visits had more often given birth 5 times or more (39\%) than women from the general population (21\%). In contrast, women who accepted screening after awareness raising campaigns had more often given birth twice or less (44\%) when compared to the general population (34\%).

The associations between screening acceptance and demographic characteristics are summarized in Table 2. Women aged 35-44 and women aged 45-59 had increased ORs of 3.52 and 7.09, respectively, for accepting the invitation in comparison with women aged 25-34. Similarly, married women had an increased OR 2.43 for accepting the screening invitation. Increased ORs for accepting screening were found among women who had attended primary or secondary school in comparison with women who had never attended screening (OR 1.81 and OR 1.94, respectively). Finally, women who had 0-2 children were more prone to accept the invitation in comparison with women who had five or more children (OR 3.21).

The 396 women, who in relation to the home visit stated they had never attended screening, were questioned about their knowledge of cervical cancer and perceived barriers for attending health check-ups (Table 3). More than half (53\%) of the women had never heard of cervical cancer. When questioned about perceived barriers for attending health check-ups, 57\% stated that difficult 
Table 1 Demographic characteristics of the general population and women who accepted the cervical cancer screening invitation via the home visit approach and awareness raising campaign

\begin{tabular}{|c|c|c|c|c|c|c|}
\hline \multirow[b]{2}{*}{ Age(years) } & \multicolumn{2}{|c|}{ General population $\mathrm{N}=6063 \%$} & \multicolumn{2}{|c|}{ Home visits $\mathrm{N}=83 \%$} & \multicolumn{2}{|c|}{ Awareness raising $\mathrm{N}=721 \%$} \\
\hline & & & & & & \\
\hline $25-34$ & 3092 & 51.0 & 38 & 45.8 & 281 & 38.9 \\
\hline $35-44$ & 2231 & 36.8 & 28 & 33.7 & 273 & 37.9 \\
\hline $45-59$ & 740 & 12.2 & 17 & 20.5 & 167 & 23.1 \\
\hline \multicolumn{7}{|l|}{ Marital status } \\
\hline Married & 3844 & 63.4 & 66 & 79.5 & 562 & 77.9 \\
\hline Single & 2219 & 36.6 & 17 & 20.5 & 159 & 22.1 \\
\hline \multicolumn{7}{|l|}{ Education } \\
\hline No schooling & 1158 & 19.1 & 6 & 7.2 & 43 & 6.0 \\
\hline Primary school & 3923 & 64.7 & 29 & 34.9 & 442 & 61.3 \\
\hline Secondary school & 982 & 16.2 & 48 & 57.8 & 236 & 32.7 \\
\hline \multicolumn{7}{|l|}{ No of children } \\
\hline $0-2$ & 2061 & 34.0 & 8 & 9.6 & 316 & 43.8 \\
\hline $3-4$ & 2728 & 45.0 & 43 & 51.8 & 259 & 35.9 \\
\hline $5+$ & 1274 & 21.0 & 32 & 38.6 & 146 & 20.3 \\
\hline
\end{tabular}

access to health service would be a hindering factor. In addition, $31 \%$ of the women stated they were reluctant to go for any test in absence of disease. Lack of medical advice and fear of being diagnosed as having cancer were additionally mentioned as a barrier by $12 \%$ and $13 \%$ of the women.

Table 4 summarizes the association between screening acceptance and the women's knowledge and awareness of cervical cancer. Awareness of cervical cancer and screening service were positively associated with screening acceptance (ORs 5.90 and 4.20, respectively).
Similarly, the women's knowledge of cervical cancer risk factors was also found to be a determining factor for screening attendance (ORs of 3.38). Finally, women who believed that cervical cancer could be prevented and women who believed screening could improve survival were also more likely to accept screening with increased ORs of 10.1 and 10.4, respectively.

\section{Discussion}

As cervical cancer screening is being increasingly implemented in developing countries, there is a need to

Table 2 Comparison of demographic characteristics of women who accepted and who did not accept a cervical cancer screening invitation

\begin{tabular}{|c|c|c|c|c|c|c|}
\hline & \multicolumn{2}{|c|}{$\begin{array}{l}\text { Accepted screening invitation } \\
\qquad \mathrm{N}=804 \%\end{array}$} & \multicolumn{2}{|c|}{$\begin{array}{c}\text { Did not accept screening } \\
\text { invitation } \mathrm{N}=313 \%\end{array}$} & \multirow[t]{2}{*}{$\begin{array}{l}\text { Accepted vs. non accepted } \\
\text { Crude OR }(95 \% \mathrm{Cl})\end{array}$} & \multirow[t]{2}{*}{$\begin{array}{l}\text { Accepted vs. non accepted } \\
\text { Adjusted* OR }(95 \% \mathrm{Cl})\end{array}$} \\
\hline Age(years) & & & & & & \\
\hline $25-34$ & 319 & 39.7 & 153 & 48.9 & 1 & 1 \\
\hline $35-44$ & 301 & 37.4 & 104 & 33.2 & 1.39 (1.02-1.88) & $3.52(2.37-5.14)$ \\
\hline $45-59$ & 184 & 22.9 & 56 & 17.9 & $1.58(1.09-2.29)$ & 7.09 (4.19-12.3) \\
\hline \multicolumn{7}{|l|}{ Marital status } \\
\hline Married & 628 & 78.1 & 214 & 68.4 & $1.18(0.82-1.84)$ & $2.43(1.18-2.20)$ \\
\hline Single & 176 & 21.9 & 51 & 16.3 & 1 & 1 \\
\hline \multicolumn{7}{|l|}{ Education } \\
\hline No schooling & 49 & 6.1 & 35 & 11.2 & 1 & 1 \\
\hline Primary school & 471 & 58.6 & 208 & 66.4 & $1.62(0.99-2.63)$ & $1.81(1.01-3.42)$ \\
\hline Sec. school & 284 & 35.3 & 70 & 22.4 & $2.90(1.69-4.96)$ & $1.94(1.13-4.01)$ \\
\hline \multicolumn{7}{|l|}{ No of children } \\
\hline $0-2$ & 324 & 40.3 & 54 & 17.2 & $3.74(2.53-5-53)$ & $3.21(1.71-7.03)$ \\
\hline $3-4$ & 302 & 37.6 & 129 & 41.2 & $1.46(1.05-2.02)$ & $1.08(0.98-2.71)$ \\
\hline $5+$ & 178 & 22.1 & 111 & 35.4 & 1 & 1.00 \\
\hline
\end{tabular}

*Adjusted for the effect of age, education, marital status and number of children. 
Table 3 Knowledge of cervical cancer and perceived barriers for attending health check ups among women who had never attended cervical cancer screening

$\mathrm{N}=396 \quad$ Percentage

(\%)

Have ever heard of cervical cancer

\begin{tabular}{|c|c|c|}
\hline Yes & 187 & 52.8 \\
\hline No & 170 & 47.2 \\
\hline Missing & 39 & \\
\hline \multicolumn{3}{|c|}{ Perceived barriers for attending health check-up* } \\
\hline Difficulty in accessing screening services & 226 & 57.1 \\
\hline Lack of health education & 34 & 8.5 \\
\hline $\begin{array}{l}\text { Reluctance to go for any test in absence of } \\
\text { disease }\end{array}$ & 123 & 31.1 \\
\hline Lack of medical advice & 46 & 11.6 \\
\hline Fear of knowing they have cancer & 50 & 12.6 \\
\hline Prohibitive cost of the test & 8 & 2.0 \\
\hline Fear of pain of test & 19 & 4.8 \\
\hline
\end{tabular}

*Add more than $100 \%$ since the women were able to respond to more than one question. consider potential determinants of acceptance of cervical cancer screening in such settings. The present study is based on data from Tanzania and reveals that screening acceptance is associated with being older, being married, having attended school, and having less than 5 children. Furthermore, knowledge and awareness of cervical cancer and screening benefits seem to have a positive impact on screening acceptance.

This study was designed to include a representative group of women from a population that had not previously attended cervical cancer screening and then assess how they responded to a screening invitation via different approaches. Thereby the study has shed light on the effect of different strategies for inviting women to cervical cancer screening. Home visits lacked efficiency in improving screening attendance due to its low acceptance rate. In contrast, the approach of decentralizing cervical cancer screening to district level and combining the decentralization with awareness raising campaigns was quite effective in making women accepting screening. Hence, cervical cancer screening attendance may be enhanced if a move is made from the current centrally

Table 4 Knowledge of cervical cancer screening service among women who accepted and women who did not accept a cervical cancer screening invitation

\begin{tabular}{|c|c|c|c|c|c|}
\hline & \multicolumn{2}{|c|}{$\begin{array}{l}\text { Accepted screening } \\
\text { invitation } \mathrm{N}=83(\%)\end{array}$} & \multicolumn{2}{|c|}{$\begin{array}{l}\text { Did not accept screening } \\
\text { invitation } \mathrm{N}=313(\%)\end{array}$} & \multirow[t]{2}{*}{$\begin{array}{l}\text { Accepted vs. non accepted } \\
\text { Crude OR }(95 \% \mathrm{Cl})\end{array}$} \\
\hline \multicolumn{5}{|c|}{ Heard about cervical cancer } & \\
\hline Yes & 68 & 81.9 & 119 & 43.4 & $5.90(3.1-11.38)$ \\
\hline No/Don't know & 15 & 18.1 & 155 & 56.6 & 1 \\
\hline Missing & 0 & & 39 & & \\
\hline \multicolumn{6}{|c|}{ Heard about screening } \\
\hline Yes & 62 & 74.7 & 116 & 41.3 & $4.20(2.35-7.56)$ \\
\hline No/Don't know & 21 & 25.3 & 165 & 58.7 & 1 \\
\hline Missing & 0 & & 32 & & \\
\hline \multicolumn{6}{|c|}{ Knowledge of cervical cancer risk factors } \\
\hline Yes & 38 & 45.8 & 62 & 20.0 & $3.38(1.96-5.83)$ \\
\hline No/Don't know & 45 & 54.2 & 248 & 80.0 & 1 \\
\hline Missing & 0 & & 3 & & \\
\hline \multicolumn{6}{|l|}{ Heard of HPV } \\
\hline Yes & 4 & 4.8 & 10 & 3.2 & $1.52(0.39-5.45)$ \\
\hline No/Don't know & 79 & 95.2 & 300 & 96.8 & 1 \\
\hline Missing & 0 & & 3 & & \\
\hline \multicolumn{6}{|c|}{ Can cervical cancer be prevented } \\
\hline Yes & 24 & 28.9 & 12 & 3.9 & $10.1(4.55-22.9)$ \\
\hline No/Don't know & 59 & 71.1 & 299 & 96.1 & 1 \\
\hline Missing & 0 & & 2 & & \\
\hline \multicolumn{6}{|c|}{ Can screening improve survival? } \\
\hline Yes & 56 & 67.5 & 52 & 16.6 & $10.4(5.82-18.7)$ \\
\hline No/Don't know & 27 & 32.5 & 261 & 83.4 & 1 \\
\hline Missing & 0 & & 0 & & \\
\hline
\end{tabular}


organized screening system to a more decentralized system where the service is offered at a few selected antenatal clinics or by mobile out-reach clinics.

The findings from the present study suggests that older women are more responsive to accept screening than younger women. A finding which is well in line with the recommendation that cervical cancer screening programs should aim at targeting older women since the benefit from screening this group of women is particularly high. It has for instance been demonstrated that participation in the UK cervical screening program by women aged 35-64 reduces the risk of cervical cancer over the next five years by $60-80 \%$ and the risk of advanced cervical cancer by about 90\% [19]. In addition, the relative protection against cervical cancer is higher in older women than in women aged 20-34 years [19]. Women of high parity comprised an identifiable subgroup that was less likely to attend screening in the setting studied. A finding which should raise concern since the enrolment of high parity women in cervical cancer screening programs is particularly important given that high parity is known to be a co-factor of HPV carcinogenesis via mechanical, hormonal and immunological mechanisms [20-22]. A possible explanation for the low screening acceptance among high-parity women may be that practical barriers such as foregoing domestic activities are more prevalent among this group of women. To reach the women most at risk of cervical cancer it is of paramount importance that reproductive health programs strive to encourage screening among high parity women. In that relation it should be stressed that home visits apparently were more effective than awareness raising campaigns in making women of high parity attend screening. Educational level did also seem to matter for women's screening acceptance. Women who had attended at least primary school were more likely to attend screening in comparison with women who had never attended school. These findings are in line with other studies that have documented that women with low education are less knowledgeable about the need for cervical screenings and have limited resources to cater for their screening attendance due to its inherent cost [23]. In addressing women's needs, it should be acknowledged that many women, in addition to economic constraints, counter problems such as long waiting time, cultural deterrents to care and poor quality of health services when attempting to access screening services. Attempts should be made to eliminate these barriers when scaling up cervical cancer screening. In addition, since wide spread routine use of VIA testing may be associated with poorer test performance $[15,24]$ more sensitive, objective and reproducible screening tests should be considered when scaling up cervical cancer screening. HPV testing in combination with
VIA testing, where the VIA test function as a triage/ treatment activity following HPV testing may be more appropriate for cervical cancer screening in developing countries [24]. One of the drawbacks with the inclusion of HPV as a primary screening method is the associated costs. However, with an increasing availability of simple, affordable, and accurate HPV tests (careHPV test, Qiagen Gaithersburg, Inc. MD, USA) that provides results within 3 hours [25] it has been suggested that cervical cancer screening in low-resource settings increasingly should be supplemented by HPV testing [24].

The knowledge and awareness of cervical cancer was in general low and screening acceptance was associated with having knowledge of cervical cancer, its risk factors and, its prevention. Poor knowledge of cervical cancer has also been found in the more general population of Tanzania [26]. A number of studies from other subSaharan African countries have similarly found that women who lack awareness of cervical cancer are less likely to participate in screening services and are thus at increased risk of developing cancer [27-29]. In our study almost half of the women (47\%) had never heard the term cervical cancer. This lack of biomedical knowledge may partly be explained by the fact that cervical cancer, despite being the most common female cancer in subSaharan Africa, is a rare condition that has not been prioritized by the national health system, advocacy programs have therefore not focused on cervical cancer [30]. More diverse strategies should be employed to convey educational health messages which take into account the women's socio economic and cultural background. In that relation it should be born in mind that experiences from both developed and developing countries have shown that conveying message via word of mouth and via audio visual channels are effective in making women more aware of cervical cancer and screening possibilities [31]. In addition, health education through trained lay persons in community centers should also be considered as this has been reported to be an effective method in other studies [32,33].

In conclusion, we have documented that there are identifiable subgroups among which cervical cancer screening can be increased in Dar es Salaam. Special attention should be paid to poorly educated women and women of high parity. Lack of knowledge of cervical cancer also contributed in preventing women from attending cervical cancer screenings. Women's perceptions and notions about cervical cancer need to be further assessed to develop communication strategies that take a broader cultural framework into account. Providing education and information orally as well as improving access to more culturally acceptable screening 
services will likely lead to increased uptake of screening services in Tanzania.

\section{Competing interests}

KKS received lecture fees, advisory board fees, and research grants through her institution from Merck and Sanofi Pasteur MSD.

\section{Authors' contributions}

KC participated in the conception, design, and implementation of the study, statistical analysis, interpretation and drafting of manuscript. KKS and RV participated in developing the study design, the implementation and the interpretation of the findings. DM, MJ, NT and TB participated in developing the study design and assisted with implementation of the study. All authors have read and approved the final manuscript.

\section{Acknowledgements}

We would like to acknowledge DANIDA (Danish International Development Agency) who supported the study financially, and Ocean Road Cancer Institute for moral and material support.

\section{Author details}

'Department of International Health, Immunology and Microbiology, University of Copenhagen, Copenhagen K, Denmark. ${ }^{2}$ Ocean Road Cancer Institute, Dar es Salaam, Tanzania. ${ }^{3}$ Department of Virus, Lifestyle and Genes, Institute of Cancer and Epidemiology, Danish Cancer Society Gynaecologic Clinic Rigshospitalet, University of Copenhagen, Copenhagen K, Denmark. ${ }^{4}$ Department of Gynaecology and Obstetrics, Odense University Hospital, Denmark.

Received: 9 April 2012 Accepted: 17 November 2012

Published: 19 December 2012

\section{References}

1. Bosch FX, Manos MM, Munoz N, Sherman M, Jansen AM, Peto J, Schiffman MH, Moreno V, Kurman R, Shah KV: Prevalence of human papillomavirus in cervical cancer: a worldwide perspective. International biological study on cervical cancer (IBSCC) Study Group. J Natl Cancer Inst 1995, 87(11):796-802.

2. Kjaer SK, Chackerian B, van den Brule AJ, Svare El, Paull G, Walbomers JM, Schiller JT, Bock JE, Sherman ME, Lowy DR, et al: High-risk human papillomavirus is sexually transmitted: evidence from a follow-up study of virgins starting sexual activity (intercourse). Cancer Epidemiol Biomarkers Prev 2001, 10(2):101-106.

3. Ferlay J, Shin HR, Bray F, Forman D, Mathers C, Parkin DM: Estimates of worldwide burden of cancer in 2008. 2008.

4. Hakama M, Coleman MP, Alexe DM, Auvinen A: Cancer screening: evidence and practice in Europe 2008. Eur J Cancer 2008, 44(10):1404-1413.

5. Sankaranarayanan R, Budukh AM, Rajkumar R: Effective screening programmes for cervical cancer in low- and middle-income developing countries. Bull World Health Organ 2001, 79(10):954-962.

6. Vizcaino AP, Moreno V, Bosch FX, Munoz N, Barros-Dios XM, Borras J, Parkin DM: International trends in incidence of cervical cancer: Il. Squamous-cell carcinoma. Int J Cancer 2000, 86(3):429-435.

7. Wabinga HR, Parkin DM, Wabwire-Mangen F, Nambooze S: Trends in cancer incidence in Kyadondo County, Uganda, 1960-1997. Br J Cancer 2000, 82(9):1585-1592.

8. Lazcano-Ponce E, Palacio-Mejia LS, Allen-Leigh B, Yunes-Diaz E, Alonso P, Schiavon R, Hernandez-Avila M: Decreasing cervical cancer mortality in Mexico: effect of Papanicolaou coverage, birthrate, and the importance of diagnostic validity of cytology. Cancer Epidemiol Biomarkers Prev 2008, 17(10):2808-2817.

9. Sepulveda C, Prado R: Effective cervical cytology screening programmes in middle-income countries: the Chilean experience. Cancer Detect Prev 2005, 29(5):405-411.

10. Guidozzi F: Screening for cervical cancer. Obstet Gynecol Surv 1996, 51(4):247-252.
11. Palanuwong B: Alternative cervical cancer prevention in low-resource settings: Experiences of visual inspection by acetic acid with single-visit approach in the first five provinces of Thailand. Aust N Z J Obstet Gynaecol 2007, 47(1):54-60.

12. Denny L, Kuhn L, De Souza M, Pollack AE, Dupree W, Wright TC Jr: Screen-and-treat approaches for cervical cancer prevention in low-resource settings: a randomized controlled trial. JAMA 2005, 294(17):2173-2181.

13. Miller $A B$, Sankaranarayanan $R$, Bosch FX, Sepulveda C: Can screening for cervical cancer be improved, especially in developing countries? Int J Cancer 2003, 107(3):337-340.

14. Deodhar K, Sankaranarayanan R, Jayant K, Jeronimo J, Thorat R, Hingmire S, Muwonge R, Chiwate A, Deshpande R, Ajit D, et al: Accuracy of concurrent visual and cytology screening in detecting cervical cancer precursors in rural India. Int J Cancer 2012, 131(6):E954-E962.

15. Dartell M: HPV infection and cervical cancer screening in HIV positive and HIV negative Tanzanian women. PhD thesis. Denmark: University of Copenhagen, Department of International Health, Immunology and Microbiology; 2012.

16. Ferlay JBF, Pisani P: Cancer Incidence, Mortality and Prevalence World Wide (version 2). Lyon, France: IARC Press; 2004.

17. Ngoma T, Muwonge R, Mwaiselage J, Kawegere J, Bukori P, Sankaranarayanan R: Evaluation of cervical visual inspection screening in Dar es Salaam, Tanzania. Int J Gynaecol Obstet 2010, 109(2):100-104.

18. Path: Report of an Africa Regional meeting on cervical cancer. 2010. http://www.rho.org/files/PATH_Africa_cxca_conf_report_2010.pdf.

19. Sasieni P, Castanon A, Cuzick J: Effectiveness of cervical screening with age: population based case-control study of prospectively recorded data. BMJ 2009, 339:b2968.

20. Munoz N, Franceschi S, Bosetti C, Moreno V, Herrero R, Smith JS, Shah $\mathrm{KV}$, Meijer CJ, Bosch FX: Role of parity and human papillomavirus in cervical cancer: the IARC multicentric case-control study. Lancet 2002, 359(9312):1093-1101.

21. Hildesheim A, Herrero R, Castle PE, Wacholder $S$, Bratti MC, Sherman $M E_{\text {, }}$ Lorincz AT, Burk RD, Morales J, Rodriguez AC, et al: HPV co-factors related to the development of cervical cancer: results from a population-based study in Costa Rica. Br J Cancer 2001, 84(9):1219-1226.

22. Autier $\mathrm{P}$, Coibion $\mathrm{M}$, Huet $\mathrm{F}$, Grivegnee AR: Transformation zone location and intraepithelial neoplasia of the cervix uteri. Br J Cancer 1996, 74(3):488-490

23. Bradley J, Risi L, Denny L: Widening the cervical cancer screening net in a South African township: who are the underserved? Health Care Women Int 2004, 25(3):227-241.

24. Cuzick J, Arbyn M, Sankaranarayanan R, Tsu V, Ronco G, Mayrand MH, Dillner J, Meijer CJ: Overview of human papillomavirus-based and other novel options for cervical cancer screening in developed and developing countries. Vaccine 2008, 26(Suppl 10):K29-K41.

25. Qiao YL, Sellors JW, Eder PS, Bao YP, Lim JM, Zhao FH, Weigl B, Zhang WH, Peck RB, Li L, et al: A new HPV-DNA test for cervical-cancer screening in developing regions: a cross-sectional study of clinical accuracy in rural China. Lancet Oncol 2008, 9(10):929-936.

26. Kidanto HL, Kilewo CD, Moshiro C: Cancer of the cervix: knowledge and attitudes of female patients admitted at Muhimbili National Hospital, Dar es Salaam. East Afr Med J 2002, 79(9):467-475.

27. Francis SA, Battle-Fisher M, Liverpool J, Hipple L, Mosavel M, Soogun S, Mofammere N: A qualitative analysis of South African women's knowledge, attitudes, and beliefs about HPV and cervical cancer prevention, vaccine awareness and acceptance, and maternal-child communication about sexual health. Vaccine 2011, 29(47):8760-8765.

28. Mbamara SU, Ikpeze OC, Okonkwo JE, Onyiaorah IV, Ukah CO: Knowledge, attitude and practice of cervical cancer screening among women attending gynecology clinics in a tertiary level medical care center in southeastern Nigeria. J Reprod Med 2011, 56(11-12):491-496.

29. Mupepi SC, Sampselle CM, Johnson TR: Knowledge, attitudes, and demographic factors influencing cervical cancer screening behavior of Zimbabwean women. J Womens Health (Larchmt) 2011, 20(6):943-952.

30. Moving cancer up the global health agenda [editorial]. Lancet 2010, 375(9731):2051. 
31. IARC: Hand books of Cancer Prevention. Lyon, France: IARC pres; 2005.

32. Johnson BA, Khanna SK: Community health workers and home-based care programs for HIV clients. J Natl Med Assoc 2004, 96(4):496-502.

33. Nabudere $H$, Asiimwe D, Mijumbi R: Task shifting in maternal and child health care: an evidence brief for Uganda. Int J Technol Assess Health Care 2011, 27(2):173-179.

doi:10.1186/1471-2458-12-1093

Cite this article as: Kahesa et al:: Determinants of acceptance of cervical cancer screening in Dar es Salaam, Tanzania. BMC Public Health 2012

12:1093.

\section{Submit your next manuscript to BioMed Central} and take full advantage of:

- Convenient online submission

- Thorough peer review

- No space constraints or color figure charges

- Immediate publication on acceptance

- Inclusion in PubMed, CAS, Scopus and Google Scholar

- Research which is freely available for redistribution 